\title{
Role Stress Revisited: One or Two Constructs?
}

\author{
By: James S. Boles and Barry J. Babin
}

James S. Boles and Barry J. Babin, "Role Stress Revisited: One or Two Constructs?", Journal of Marketing: Theory and Practice 2 (no. 3 Summer, 1994), 57-69.

https://doi.org/10.1080/10696679.1994.11501659

This is an Accepted Manuscript of an article published by Taylor \& Francis in Journal of Marketing: Theory and Practice on 21 December 2015, available online: http://www.tandfonline.com/10.1080/10696679.1994.11501659. It is deposited under the terms of the Creative Commons Attribution-NonCommercial License (http://creativecommons.org/licenses/by-nc/4.0/), which permits non-commercial re-use, distribution, and reproduction in any medium, provided the original work is properly cited.

\begin{abstract}
:
This paper extends previous efforts examining the construct validity of role stress. While some see it as comprised of separate role conflict and role ambiguity factors, others argue that it is a unidimensional construct. The authors use recent advancements in measurement theory to test the two competing theories. The results support the two-factor model rather conclusively. Implications for theory and practice are suggested.
\end{abstract}

Keywords: role stress | role ambiguity | role conflict | salespeople

\section{Article:}

Work-related role stress is one of the most widely researched constructs in organizational behavior. Over 100 studies and three reviews (including meta-analyses) of the topic have been published in the last two decades (Jackson and Schuler 1985; McGee, Ferguson, and Seers 1989). Organizational researchers typically define role stress as all aspects of conflict and ambiguity associated with a particular work-related role (e.g., Bedeian, Burke, and Moffett 1988; Leigh, Lucas, and Woodman 1988; Teas 1983). Furthermore, "[i]n most salesforce research, role conflict and role ambiguity are treated as independent aspects of role stress" (Behrman and Perreault 1984, p. 12).

Although role conflict and role ambiguity are sometimes conceptualized as inseparable components of employees' role stress, Rizzo, House and Lirtzman (1970) draw the following distinctions between the two concepts. Role conflict (RC) is defined as the degree to which an individual perceives him/her self to be faced with incompatibilities in job requirements. For example, doing a job as instructed when he/she feels this is not the most productive approach. Role ambiguity (RA) represents an employee's lack of clarity regarding performance expectations relative to others' role expectations and one's own expectancy-related uncertainty. 
Both RC and RA exert tremendous direct and/or indirect influence on a variety of workplace attitudes and behaviors. Previous studies indicate that RC and RA reduce job satisfaction, organizational commitment, and performance (Fisher and Gitelson 1983; Jackson and Shuler 1985). Research also suggests that these role constructs can influence the likelihood of an employee leaving a position (Fisher and Gitelson 1983).

Despite the strength of these findings, however, there remains a question concerning whether items measuring role stress indicate " ... unique, distinguishable constructs [RA and RC] or whether they are only different indicators of one general construct" (McGee, Ferguson, and Seers 1989 , p. 815). This is an important issue given the nature of measurement error associated with RA and RC applications. Netemeyer, Johnston and Burton (1990) is one of few studies examining this issue specifically. They illustrate the importance of proper conceptualization by suggesting that relationships found between role stress and other latent variables may be biased and misleading due to measurement error. Further, inaccurate measurement assessment may account for some mixed findings across different studies of role stress and associated repercussions. Pragmatically, the lack of a clear understanding about RC's and RA's true nature makes forming policy difficult. The basic question of concern to managers is whether or not there are one or two organizational components to manage as they attempt to build an effective work environment.

The role stress measures employed most often (Rizzo, House, and Lirtzman 1970), hypothesizing separate RA and RC factors, have yielded mixed measurement results (Netemeyer, Johnston and Burton 1990). The scale exhibit, acceptable psychometric properties in some previous applications-showing evidence of convergence and discrimination (e.g., House, Schuler, and Levanoni 1983). In recent years, however, other researchers have questioned the scale's validity (Howell, Bellenger, and Wilcox 1987; McGee, Ferguson and Seers 1989).

This study's purpose is to build on recent research examining empirically the proper operationalization of role stress (Netemeyer, Johnston and Burton 1990). The two predominant operationalizations ( 1 factor vs. 2 factors) are discussed and compared using confirmatory factor analysis. In addition, this study examines the nature of role stress amidst the turbulence of the retail environment. The majority of previous applications have been in nonretail settings. Prior evidence suggest that the retail environment presents unique and dynamic conditions affecting employees' organizational behavior (e.g., Darden, Hampton, and Howell 1989; Teas 1981). Relatively high turnover rates, for example, are a nagging problem for retailers and may be partially attributable to increased role stress (Good, Sisler, and Gentry 1988). Thus, we seek to provide additional evidence as to which conceptualization is most appropriate and more specifically, to examine the appropriate conceptualization in a dynamic retail environment. Examination of this issue is particularly timely given recent advances in measurement theory that allow a more rigorous and precise test among plausible measurement models (e.g., Anderson and Gerbing 1988; Gerbing and Anderson 1988).

We begin by highlighting briefly previous research examining role stress and its consequences. Next, a study is described that allows a comparison of the competing theories. Finally, theoretical and practical implications are suggested. 


\section{LITERATURE}

Previous research has identified RC and RA as antecedents of a variety of work-related attitudes and behaviors (e.g., Bedeian and Armenakis 1981; Behrman and Perreault 1984). Studies of industrial salespeople, for instance, show that both variables are significantly, and negatively related to job satisfaction (Netemeyer, Johnston and Burton 1990; Teas 1983). In contrast, role conflict and role ambiguity affect salesperson performance less consistently. While significant covariation is generally found, the relationships' direction varies (Behrman and Perreault 1984; Dubinsky and Hartley 1986). Role conflict appears to influence sales performance positively (Behnnan and Perreault 1984) while role ambiguity may have a negative effect on performance levels (Bagozzi 1978; Dubinsky and Hartley 1986). In part, mixed findings like these coincide with questions about scale validity.

Surprisingly, relatively few studies have examined role stress in the retail work-place. One study, however (Good, Sisler, and Gentry 1988), found increased levels of conflict and ambiguity were related directly to retail employees' job satisfaction. This supports research in nonretail contexts that suggests influences of RC and RA on job satisfaction are quite strong and are direct (Jackson and Schuler 1985).

These findings leave little doubt about the relevance of employees' role stress perceptions. However, the existing literature is far less agreeable concerning the construct validity of role stress measures (RC and RA items); an issue that is the focus of this study. Tracy and Johnson (1981), for example, suggest that differences between RC and RA in the Rizzo, House and Lirtzman (1970) scales are linguistic rather than conceptual or empirical. That is, they suggest role stress as a unidimensional concept. On the other hand, House, Schuler and Levanoni (1983) argue that RC and RA represent two different but related role stress components. Their results identify role ambiguity as a condition that is generated both internally and externally. They also suggest that role conflict may be more limited than role ambiguity and can be "thought of as a stressful condition caused by others" (House, Schuler and Levanoni 1983, p. 337).

The debate continues in more recent studies. McGee, Ferguson and Seers (1989), examining public employees, concluded, similarly to Tracy and Johnson (1989), that role conflict and role ambiguity are indistinguishable. These results indicate that items assessing work-related RA are merely negative indicants of the same construct assessed by RC items. Meta-analyses of RC and RA also indicate that effects of these constructs on a wide range of job-related attitudes and behaviors are very similar (Fisher and Gitelson 1983; Jackson and Schuler 1985). In addition, King and King (1990) criticize the content validity of the Rizzo, House and Lirtzman (1970) measures.

In contrast to those views, Netemeyer, Johnston and Burton (1990, p. 152), report results comparing the unidimensional (role stress) versus the two-factor (separate RC and RA constructs) solution that offer "... support for the convergent and discriminant validity of the scales". Thus, a two factor-model is suggested. Further support for viewing RC and RA a5 different construe, $1 \mathrm{~s}$ can be drawn indirectly from previous sales research that has often demonstrated differences in the relationships of RC and RA with performance (e.g., Behrman and Perreault 1984; Dubinsky and Hartley 1986). Finding that RC positively influences 
performance while RA has a negative effect on that construct provides some evidence that RC and RA may not be one construct.

In summary, the effects of these role variables on a wide range of work-related attitudes and behaviors is well documented across a variety of employment positions. However, in some cases, such as salesperson performance prediction, RC and RA have been found to affect constructs in opposite directions. As the review of previous studies indicates, there remains considerable confusion concerning the precise nature of these role perceptions. At present, some researchers view them as a single measure of role stress, while others still support the view that RC and RA represent two distinct constructs. It appears that in boundary spanning positions, the two construct view has some empirical support (Netemeyer, Johnston and Burton 1990), while in other types of employment (i.e. management positions) the unidimensional conceptualization of role stress may prove valid (McGee, Ferguson and Seers 1989). The current study's specific intent is to compare empirically, in a retail sales setting, an hypothesized unidimensional model (Figure 1) against the alternative two-factor model (Figure 2). The study described below is intended to address this end.

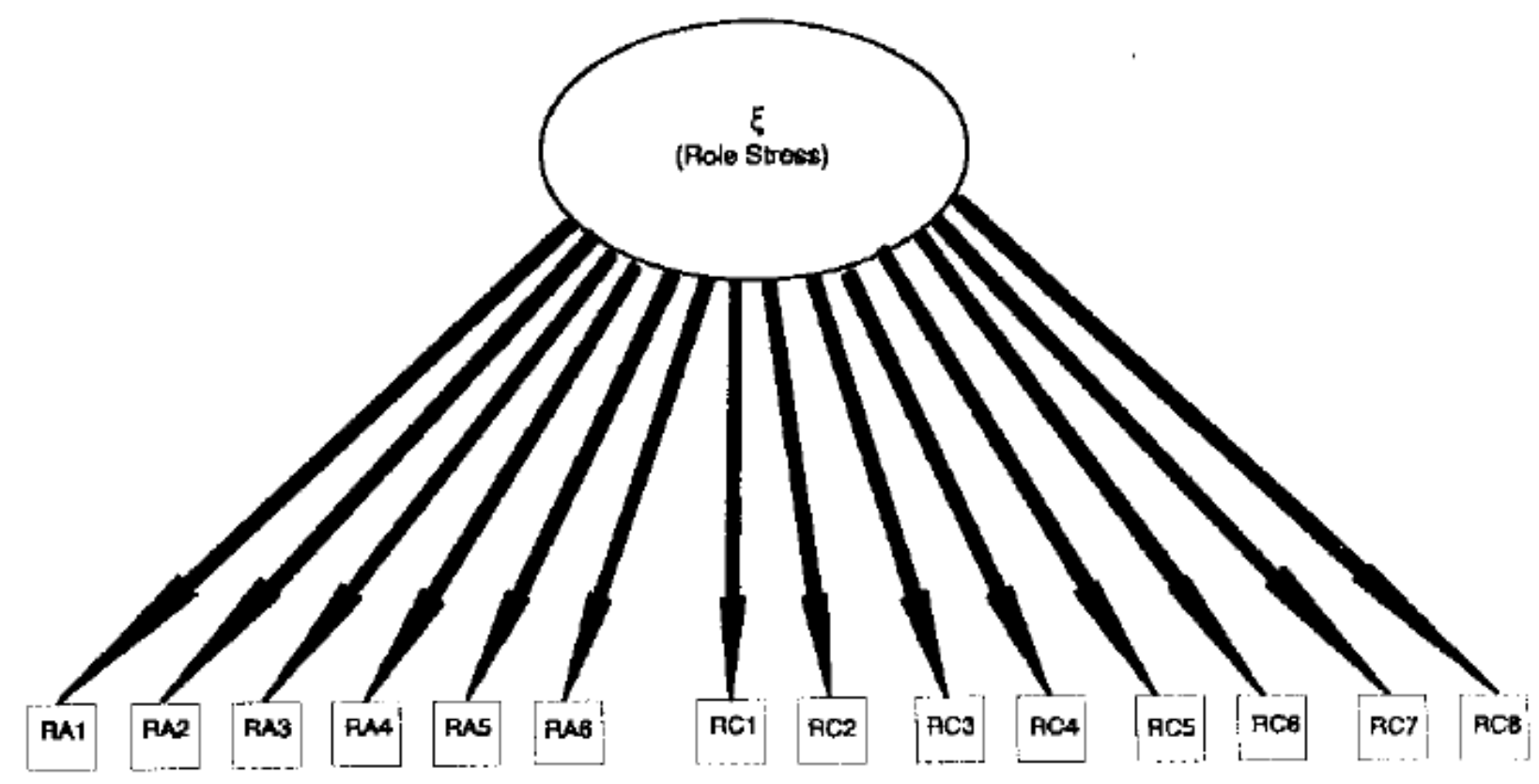

Figure 1. 1-Factor Role Stress Model 


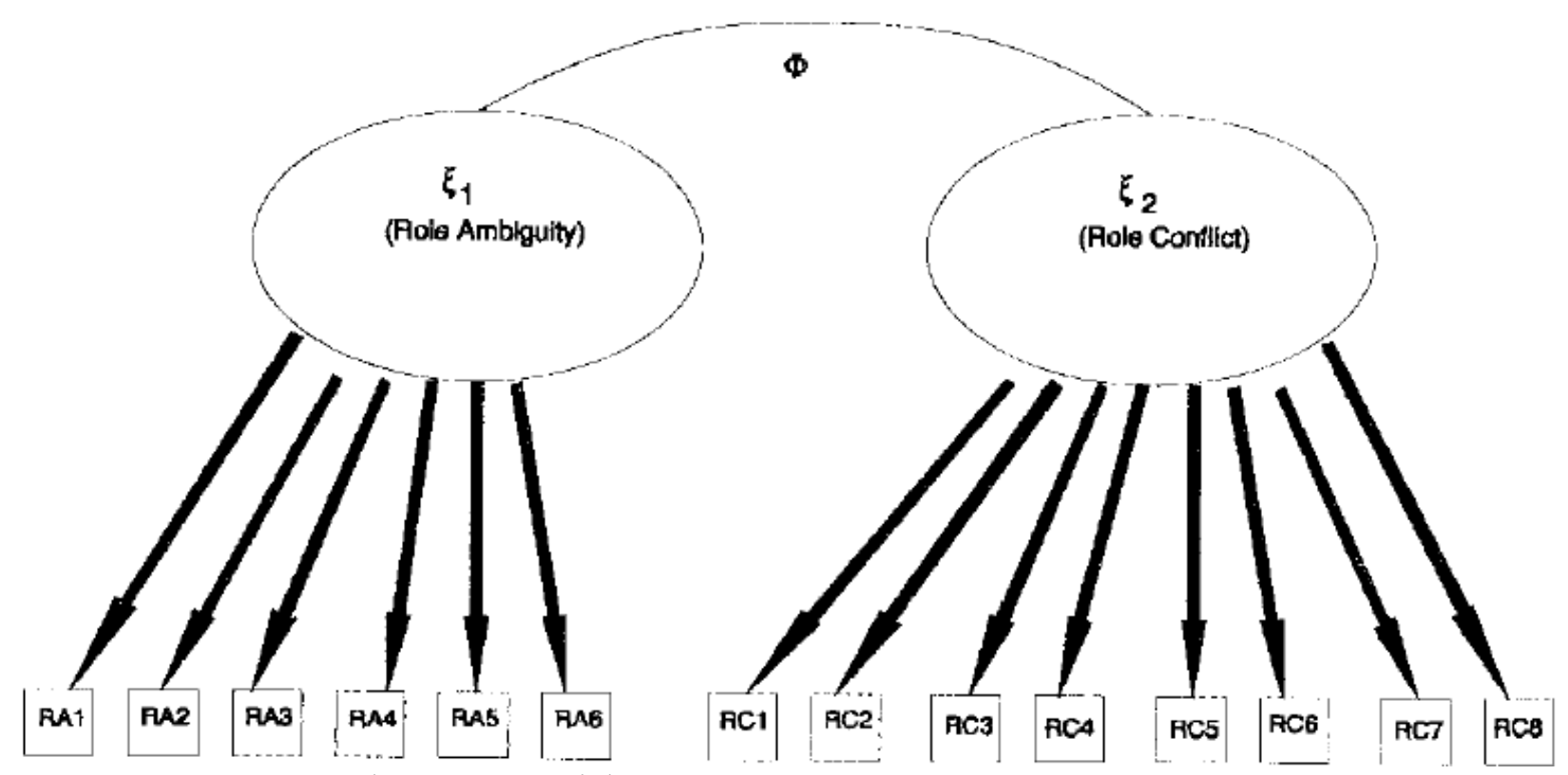

Figure 2. 2-Factor Role Stress Model

\section{RESEARCH METIIODS}

\section{Data Collection}

\section{Sample.}

Data for this study were collected from commissioned retail employees representing a variety of different retail establishments. The price points of stores included in the study range from "average" to "up-scale" and appeal to the corresponding socio-economic consumer segments. Participating firms were located within, or nearby, one of several regional shopping malls in a large southeastern city. The product lines were those normally found in these types of stores. The sample ranged from stores employing as few as 25 employees to those employing over 100 . However, no discount stores (e.g., Walmart, K-mart) were included since they do not generally employ commissioned salespeople.

Survey instruments were distributed at staff meetings by the research team. After presenting a brief explanation of the research's intentions, surveys were distributed to respondents who filled out the questionnaires and returned them at the end of the meeting. Respondent anonymity was assured in the instructions. In addition, completed surveys were sealed in a plain envelope and then dropped into a large unattended collection box.

Approximately 350 surveys were distributed. Of those, 291 had complete information and are included in these analyses. The average survey respondent was 27 years of age and had almost six years work experience. In addition, more than eighty percent had a college degree or were enrolled in college.

\section{Measures.}


This study uses the 14-item Rizzo, House, and Lirtzman (1970) role stress measure. Scale items are described in the Appendix. This scale has been used extensively in organizational research for both marketing and management studies (Johnston et al. 1990). Eight and six items purportedly represent RC and RA, respectively. All items were assessed on a 5-point scale with 1 $=$ strongly disagree and $5=$ strongly agree. In addition, multi-item job performance and job satisfaction indices were administered.

Results

Confirmatory factor analysis (CFA) was used to compare the validity of each proposed model. Further rigorous validation procedures are based primarily on procedures set forth in Anderson and Gerbing (1988) and Gerbing and Anderson (1988). These procedures examine construct validity through independent assessments of convergence and discrimination.

Table 1 provides maximum likelihood factor loading estimates for each model. All loading estimates, for both models, are highly significant $(\mathrm{p}<.001)$ providing evidence of convergence. The corresponding individual-item reliabilities range from a low of .13 to a high of .51 for model 1. For model two, these reliabilities range from .15 to .57 . Scale reliabilities are not appropriate at this point because unidimensionality has yet to be established (Gerbing and Anderson 1988).

Table 1. Maximum Likelihood Factor Loading Estimates

\begin{tabular}{|lccc|}
\hline & Model 1 & \multicolumn{2}{c|}{ Model 2 } \\
\cline { 2 - 4 } Variable & Role Stress & Role Ambiguity & Role Conflict \\
\hline RA1 & .50 & .75 & \\
RA2 & .43 & .58 & \\
RA3 & .46 & .69 & \\
RA4 & .38 & .63 & \\
RA5 & .53 & .63 & .70 \\
RA6 & .32 & .40 & .47 \\
RC1 & .63 & & .65 \\
RC2 & .40 & & .58 \\
RC3 & .61 & & .73 \\
RC4 & .60 & & .59 \\
RC5 & .71 & & .51 \\
RC6 & .53 & & .39 \\
RC7 & .51 & & \\
RC8 & .36 & & \\
\hline
\end{tabular}

Table 2 shows the overall fit statistics resulting from each CF A Model 1 produced a $\chi^{2}$ residual of 389.2 with 77 degrees of freedom ( $p<.001)$. The goodness of fit index $(\mathrm{GFI})$ and comparative fit index are .77 and .67 respectively. Each of these approach accepted standards noted in the marketing literature (see Netemeyer, Durvasula, and Lichtenstein 1991).

Model 2 produced a $\chi^{2}$ residual of 159.8 with 76 degrees of freedom $(\mathrm{p}<.001)$. The GFI and CFI are .92 and .91 respectively. The $\chi^{2}$ to degrees of freedom ratio is 2.1 and the root-mean-square residual is .06. These statistics, quite noticeably, are an improvement over model 1. In addition, they are within generally accepted benchmarks for overall fit. 
Table 2. Model Fir Statistics

\begin{tabular}{|lcc|}
\hline Statistic & Model 1 & Model 2 \\
\hline$\chi^{2}$ & 389.2 & 159.8 \\
df & 77 & 76 \\
$\chi^{2}:$ df Ratio & 5.5 & 2.1 \\
GFI & .77 & .92 \\
CFI & .67 & .91 \\
RMSR & .11 & .06 \\
\hline
\end{tabular}

However, since the comparison addresses discriminant validity directly, more rigorous examinations of this issue were conducted. If RC and RA represent distinct constructs, the two factor model should represent a significant improvement in fit compared to the unidimensional model. A $\chi^{2}$ difference test was conducted examining this possibility (Anderson and Gerbing 1988; Gerbing and Anderson 1988; Netemeyer, Durvasula and Lichtenstein 1991). The $\chi^{2}$ difference statistic between these two models is 229.4 (389.2 - 159.8) with 1 (77-76) degree of freedom suggesting a significantly improved fit in the less parsimonious two-factor model $(\mathrm{p}<$ .001). Further, this test, in a two-factor condition, is equivalent to testing discrimination by comparing a lesser constrained model to one constraining the $\phi$ coefficient between constructs to 1.0 (see Anderson and Gerbing 1988).

An additional test of discriminant validity was conducted by comparing the percent of variation explained in each factor to the square of the correlation estimate between them (Fornell and Larcker 1981). The model 2 results indicate that RA and RC account for 39 and 35 percent of the total variance in those items, respectively. Each of these figures exceeds .20, the square of the $\phi_{2,1}$ coefficient (-.45) representing interfactor correlation. Thus it appears clear that in this data, $\mathrm{RA}$ and $\mathrm{RC}$ are separate and distinct constructs.

Yet another exploration of this issue was conducted by examining RA and RC's relation with the job performance data collected in conjunction with this study. Correlation estimates were computed between these measures indicating a positive relation between RC and performance $(\phi$ $=.16 ; \mathrm{p}<.05)$ and a negative relation between RA and performance $(\phi=-.20 ; \mathrm{p}<.05)$. These results support further each scale's distinctiveness.

Overall, the results are relatively conclusive. The two-factor model produced far superior empirical results than did the one factor model. It displays acceptable convergence as indicated by the overall fit statistics, loading estimates, and scale reliabilities $(\alpha=.78$ and .79 for RA and $\mathrm{RC}$, respectively). Further, each factor is distinct. The one factor model, assuming RA and RC are indistinguishable components of role stress, lacks unidimensionality. Thus, greater construct validity is presented in the two-factor model treating RC and RA as separate stress-related factors.

\section{DISCUSSION}

Theoretical Implications 
Our findings are consistent with Netemeyer, Johnston and Burton (1990) suggesting two distinct role stress factors - RC and RA - in sales environments. The different context considered here, retailing, did not affect the operationalization of role stress. 'The two-factor model displays construct validity as indicated by confirmatory factor analysis. Arguments like those suggesting that RA items are only distinct linguistically are not supported here. Had this been the case, high correlation between RA and RC should have been observed as opposed to the modest interrelationship suggested here. In fact, the correlation should have approached -1 . Thus, additional empirical support is provided for the two-factor model.

Further research could investigate this matter even more closely. For example, advancing psychometric techniques may allow an investigation of the extent to which wording accounts for attenuation in cross-factor item correlations. These techniques may eventually allow examination of the factor structure corrected for any subsequent linguistic bias (Darden, Dorsch, and Babin 1993).

Future researchers may also consider adding additional items in an attempt to investigate the content of the scale more closely. For example, it would be a simple matter to add some items worded toward low (high) RA (RC). Another possibility for future research would be consideration of multiple, hierarchical, conceptual role stress levels. Operationally, this would require the use of higher order confirmatory factor analysis (e.g., Gerbing, Abadi, and Patton 1987) and have implications for marketing and organizational researchers constructing structural models of employee behavior.

Further, this study's results help explain the apparently inconsistent results observed in earlier studies showing quite different results associated with RA and RC. Since the two-factors are related but distinct, it is quite reasonable to expect contrasting findings. Thus, results in sales contexts demonstrating positive relationships between $\mathrm{RC}$ and performance and negative relationships between RA and performance are understandable. Indeed these findings were replicated here.

\section{Managerial Implications}

Finally, and perhaps most importantly, an increased understanding of stress and its components is relevant for practicing sales managers. Our results support two separate but modestly interrelated constructs. The increasing evidence that $\mathrm{RA}$ and $\mathrm{RC}$ are distinct across various marketing contexts would seem to have important pragmatic consequences. More than simply understanding the distinction, managers may find that each construct can be controlled through directed policy making.

For example, sales managers should understand that conflict and ambiguity among his/her salesforce can produce different results. While it may seem counter-intuitive at first, increased $\mathrm{RC}$ can lead to higher levels of sales performance. Alternatively, increased RA can lower performance. On closer inspection however, these results may not be so surprising. High levels of $\mathrm{RC}$ indicate a work environment where employees are regularly faced with choices. A positive $\mathrm{RC}$ - performance relationship may indicate that although employees are routinely faced with the dilemma of satisfying one concern at another's expense (e.g., customer - manager, floor 
manager - store manager, manager - supervisor etc.), their decision-making generally turns out in the firm's best interest. That is, employees can sometimes be trusted to make a good decision. From a market-orientation standpoint, this is hardly surprising since salespeople are on the front line facing consumers constantly and their ability to adjust to changing consumer demands is a key-factor in firm success (Jaworski and Kohli 1993). On the other hand, employees should have an unambiguous understanding of management's expectations about their performance in light of the firm's overall goals. Effective use of this study's findings may require relatively delicate managerial policy adjustments. The scenario described below attempts to illustrate this situation.

A salesperson is presented with RC regularly; he/she is constantly faced with different concerns' incompatible requests. Now, for instance, he/she may have to decide to conform with either a customer's or a supervisor's desires. Perhaps some unit-pricing, substitution, or delivery policy may need to be broken to get a customer's business. On the other hand, satisfying the linesupervisor by conforming to the rule could mean losing a sale. Thus, conflict is clearly present. A positive $\mathrm{RC}$ - performance relationship indicates that, more often than not, a salesperson in this situation will make the right decision. Thus, salespeople should be given the flexibility to adapt within the overall goal of the firm.

Sales managers should realize that conflict is generally present and can be positive. Further research is needed to understand precisely how much conflict is optimal. That is, conflict, like other surgent variables, is likely to have a positive influence only within limits (Anderson 1990). One might hypothesize an inverted $U$ type relationship using this analogy. While some conflict is beneficial, too much may create stress levels that employees are unable to cope with on a day-today basis and could lead to increased turnover.

Ambiguity would be present in the example above if the salesperson is unclear concerning consequences associated with rule-bending. RA of this type might be driven by inconsistent treatment of salespersons violating company rules in an attempt to win business. Our results suggest that ambiguity should be avoided. Salespeople should be given unambiguous direction regarding management's expectations of their overall performance. For example, each salesperson should have a clear understanding of how far he/she should go to gain business or satisfy a customer.

Further, marketing practitioners would benefit greatly from a more concise understanding of how role stress, RA and RC, relate to other organizational variables. For example, what are the implications of high RA and/or RC on job satisfaction and turnover? Are these relationships direct or indirect? What creates RA and RC? Are these wholly or partially controllable variables? Answers to important pragmatic and theoretical questions such as these may be provided by the accumulating body of knowledge concerning role stress and its organizational antecedents and consequences.

\section{REFERENCES}

Anderson, James C. and David W. Gerbing (1988), "Structural Equation Modeling in Practice: A Review and Recommended Two-Step Approach," Psychological Bulletin, 103 (November), 411-423. 
Anderson, Kristen Joan (1990), "Arousal and the Inverted-U Hypothesis: A Critique of Neiss's 'Reconceptualizing Arousal,"' Psychological Bulletin, 107 (January), 96-100.

Bagozzi, Richard P. (1978), "Salesforce Performance and Satisfaction as a Function of Individual Difference, Interpersonal, and Situational Factors," Journal of Marketing Research, 15 (November), 517-531.

_ , and Achilles A Annenakis (1981), "A Path-Analytic Study of the Consequences of Role Conflict and Role Ambiguity," Academy of Management Journal, 24 (June), 417-424.

Bedeian, Arthur G., Beverly G. Burke, and Richard G. Moffett (1988), "Outcomes of WorkFamily Conflict Among Married Male and Female Professionals,' Journal of Management 14 (3), 417-424.

Behrman, Douglas, H and William D. Perreault, Jr. (1984), "A Role Stress Model of the Performance and Satisfaction of Industrial Salespersons," Journal of Marketing, 48 (Fall), 9-21.

Darden, William R, Michael J. Dorsch, and Barry J. Babin (1993), "The Identification and Control of Halo Error," in the Proceedings of the American Marketing Association's Annual Summer Educator's Meeting, David W. Cravens and Peter R Dickson, (eds.), Chicago, IL: American Marketing Association, 320-329.

Darden, William R, Ronald Hampton, and Roy D. Howell (1989), "Career Versus Organizational Commitment: Antecedents and Consequences of Retail Salespeople's Commitment," Journal of Retailing, 65 (Summer), 141-160.

Dubinsky, Alan J. and Steven W. Hartley (1986), "A Path-Analytic Study of a Model of Salesperson Performance," Journal of the Academy of Marketing Science, 4 (Spring), 3646.

Fisher, Cynthia D. and Richard Gitelson (1983), "A Meta-Analysis of the Correlates of Role Conflict and Ambiguity," Journal of Applied Psychology, 68 (April), 320-333.

Fornell, Claes and David F. Larcker (1981), "Evaluating Structural Equations Models with Unobservable Variables and Measurement Error," Journal of Marketing Research, 18 (February), 39-50.

Gerbing, David W., Stephan A Abadi, and Jim H Patton (1987), "Toward a Conceptualization of Impulsivity: Components across the Behavioral Self-Report Domains," Multivariate Behavioral Research, 22 (July), 357-379.

Gerbing, David A and James C. Anderson (1988), "An Updated Paradigm for Scale Development Incorporating Unidirnensionality and Its Assessment," Journal of Marketing Research, 25 (May), 186-192.

Good, Linda K, Grovalynn F. Sisler and James W. Gentry (1988), "Antecedents of Turnover Intentions Among Retail Management Personnel," Journal of Retailing, 64 (Fall), 295 314.

House, Robert J., Randall S. Schuler, and Eliahu Levanoni (1983), "Role Conflict and Ambiguity Scales: Reality or Artifacts?," Journal of Applied Psychology, 68 (April), 334-337. 
Howell, Roy D., Danny N. Bellenger, and J. B. Wilcox (1987), "Self-Esteem, Role Stress, and Job Satisfaction among Marketing Managers," Journal of Business Research, 15 (1), 7184

Jackson, Susan E. and Randall S. Schuler (1985), "A Meta-Analysis and Conceptual Critique of Research on Role Ambiguity and Role Conflict in Work Settings," Organizational Behavior and Human Decision Processes, 36 (August), 16-78.

Jaworski, Bernard J. and Ajay K. Kohli (1993), "Market Orientation: Antecedents and Consequences," Journal of Marketing, 57 (July), 53-70.

Johnston, Mark W., Charles M Futrell, A Parasuraman, and William C. Black (1990), "A Longitudinal Assessment of the Impact of Selected Organizational Influences on Salespeople's Organizational Commitment During Early Employment," Journal of Marketing Research, 27 (August), 333-344.

King, Lynda A and Daniel W. King (1990), "Role Conflict and Role Ambiguity: A Critical Assessment of Construct Validity," Psychological Bulletin, 107 (1), 48-64.

Leigh, James H, George H Lucas, Jr., and Richard W. Woodman (1988), "Effects of Perceived Organizational Factors on Role Stress-Job Attitude Relationships," Journal of Management 14 (1), 41-58.

McGee, Gail W., Carl E. Ferguson, and Anson Seers (1989), "Role Conflict and Role Ambiguity: Do the Scales Measure These Two Constructs?" Journal of Applied Psychology, 74 (October), 815-818.

Netemeyer, Richard G., Srinivas Durvasula, and Donald R Lichtenstein (1991), "A CrossNational Assessment of the Reliability and Validity of the CETSCALE," Journal of Marketing Research, 28 (August), 320-327.

— Mark W. Johnston, and Scot Burton (1990), "Analysis of Role Conflict and Role Ambiguity in a Structural Equations Framework," Journal of Applied Psychology, 75 (April), 148-157.

Rizzo, John R, Robert J. House, and Sidney I. Lirtzman (1970), "Role Conflict and Ambiguity in Complex Organizations," Administrative Science Quarterly, 15 (June), 150-163.

Teas, Kenneth R (1981), "A Test of a Model of Department Store Salespeople's Job Satisfaction," Journal of Retailing, 57 (Spring), 3-25.

(1983), "Supervisory Behavior, Role Stress, and the Job Satisfaction of Industrial Salespeople," Journal of Marketing Research, 20 (February), 84-91.

Tracy, Lane and Thomas W. Johnson (1981), "What Do the Role Conflict and Role Ambiguity Scales Measure?," Journal of Applied Psychology, 66 (August), 464-469.

\section{APPENDIX. DESCRIPTION OF SCALE ITEMS (RIZZO, HOUSE and LIRTZMAN 1970)}

\section{Role Ambiguity:}




\section{$\underline{\text { Abbreviation }} \underline{\text { Item }}$}

\begin{tabular}{ll}
\hline RA1 & I know exactly what is expected of me. \\
RA2 & I feel certain about how much authority I have. \\
RA3 & There are clear, planned goals and objectives for my job. \\
RA4 & I know what my responsibilities are. \\
RA5 & The explanation is clear as to what has to be done. \\
RA6 & I know that I have divided my time properly.
\end{tabular}

\section{Role Conflict:}

\section{Abbreviation Item}

$\mathrm{RC} 1$

$\mathrm{RC} 2$

$\mathrm{RC} 3$

$\mathrm{RC} 4$

RC5

RC6

$\mathrm{RC} 7$

$\mathrm{RC} 8$
I do things that are apt to be accepted by one person and not accepted by others. I work with two or more managers who operate quite differently. I receive incompatible requests from two or more people.

I work on unnecessary things.

I receive an assignment without adequate resources and materials to execute it. I sometimes have to bend a rule or policy in order to carry out an assignment. I receive an assignment without the manpower to complete it. There are parts of my job that should be done differently. 